\title{
Vapor-liquid equilibrium of carbon dioxide with ethyl caproate, ethyl caprylate and ethyl caprate at elevated pressures
}

\author{
Weng-Hong Hwu, Jaw-Shin Cheng, Kong-Wei Cheng, Yan-Ping Chen* \\ Department of Chemical Engineering, National Taiwan University, Taipei, Taiwan, ROC
}

Received 16 July 2002; accepted 30 January 2003

\begin{abstract}
Vapor-liquid equilibrium (VLE) data were measured for $\mathrm{CO}_{2}$ with ethyl caproate, ethyl caprylate, and ethyl caprate using a semi-flow type apparatus at 308.2, 318.2 and 328.2 K over the pressure range from 1.6 to 9.2 MPa. In this paper, VLE data are reported. The VLE data were also correlated using the Soave-Redlich-Kwong and the Peng-Robinson equations of state with various mixing rules. It is shown that both equations of state agreed well with the experimental data.
\end{abstract}

(c) 2003 Elsevier B.V. All rights reserved.

Keywords: Vapor-liquid equilibrium; Carbon dioxide; Esters; High pressure; Data

\section{Introduction}

Vapor-liquid equilibrium (VLE) data at elevated pressures are becoming important owing to the increasing applications of the dense gases or supercritical fluids. Carbon dioxide is the most commonly used supercritical fluid for extraction and materials processing because of its non-toxicity and low critical temperature and pressure. VLE data for carbon dioxide with esters at high pressure are not adequate [1]. Recently, some experimental data for carbon dioxide with esters are presented in literature [2,3], which are useful for thermodynamic modeling and process design. However, solubility data for carbon dioxide in esters at high pressures are limited. In this study, a semi-flow apparatus was used to measure the VLE data

* Corresponding author. Fax: +886-2-2362-3040.

E-mail address: ypchen@ccms.ntu.edu.tw (Y.-P. Chen). at high pressures for three binary systems of $\mathrm{CO}_{2}$ with ethyl caproate, ethyl caprylate, and ethyl caprate. Ethyl caproate $\left(\mathrm{C}_{8} \mathrm{H}_{16} \mathrm{O}_{2}\right)$ and ethyl caprate $\left(\mathrm{C}_{12} \mathrm{H}_{24} \mathrm{O}_{2}\right)$ are used in either organic synthesis or the production of essential oil. Ethyl caprylate $\left(\mathrm{C}_{10} \mathrm{H}_{20} \mathrm{O}_{2}\right)$ is used in the manufacturing of cosmetics or in food industry. The experimental measurements were carried out at temperatures of $308.2,318.2$, and $328.2 \mathrm{~K}$. The pressure ranged from 1.6 to $9.2 \mathrm{MPa}$. The experimental data were also correlated using the Soave-Redlich-Kwong (SRK) [4] and the Peng-Robinson (PR) [5] equations of state with various mixing rules.

\section{Experimental}

\subsection{Chemicals}

Liquefied carbon dioxide was available with purity more than 99.8 mass percentage from San-Fu 


\begin{tabular}{|ll|}
\hline Nomenclature & \\
$a, b$ & parameters in the equation of state \\
$K$ & equilibrium ratio, $K=y / x$ \\
$k, m$ & binary interaction parameters in the mixing rules \\
$P$ & pressure \\
$P^{\mathrm{vp}}$ & vapor pressure of ester compound \\
$R$ & gas constant \\
$T$ & temperature \\
$V$ & volume of $\mathrm{CO}_{2}$ \\
$v$ & molar volume \\
$x$ & mole fraction of liquid phase \\
$y$ & mole fraction of vapor phase \\
Subscripts & critical point \\
c & component $i$ or $j$ \\
$i, j$ & \\
Superscripts & calculated \\
cal & experimental \\
exp & \\
\hline
\end{tabular}

Chemical Co (Taiwan). Ethyl caproate, ethyl caprylate, and ethyl caprate were purchased from Acros Co. The purity of these chemicals was more than $99 \%$. All chemicals were used without further purification. Refractive indices and density are shown in Table 1 . The refractive indices of the pure compounds were measured at $293.2 \pm 0.1 \mathrm{~K}$ using an Abbe refractometer, Atago 3T, with an accuracy of \pm 0.0001 . The densities of pure chemicals were measured at $293.2 \pm 0.1$ $\mathrm{K}$ using the Anton Paar DMA 60/602 density meter with an accuracy of $\pm 1.0 \times 10^{-2} \mathrm{~kg} \mathrm{~m}^{-3}$.

\subsection{Apparatus}

A semi-flow phase equilibrium apparatus used in this study is shown in Fig. 1. The apparatus was com- posed of three sections as the sample loader, equilibrium cell, and composition analyzer. Similar experimental apparatus and procedures have been reported in the previous literature [6,7].

Pure $\mathrm{CO}_{2}$ from a high pressure container was liquefied through a cooler with the temperature between 268 and $263 \mathrm{~K}$. It was then compressed by a metering pump (ConstaMetric 3200 P/F, LCD Analytical Inc), and was heated through a pre-heating coil immersed in a water bath before charging into the pre-saturation and phase equilibrium cells. Each head of the pump was equipped with a cooling jacket, and aqueous alcohol at a temperature between 268 and $263 \mathrm{~K}$ was circulated to improve the fluid compression. A desired pressure was set in the experiment and a back pressure regulator (Tescom) was used to maintain

Table 1

Comparison of the measured refractive indices and densities of pure fluids with literature data

\begin{tabular}{|c|c|c|c|c|c|}
\hline \multirow[t]{2}{*}{ Component } & \multicolumn{2}{|l|}{$n^{\mathrm{D}}(293.2 \mathrm{~K})$} & \multicolumn{2}{|c|}{$\rho\left(293.2 \mathrm{~K}, \mathrm{~kg} \mathrm{~m}^{-3}\right)$} & \multirow[t]{2}{*}{ Purity (mass\%) } \\
\hline & Experimental & Literature [13] & Experimental & Literature [13] & \\
\hline Ethyl caproate & 1.4070 & 1.4073 & 871.2 & 873.0 & $>99.0$ \\
\hline Ethyl caprylate & 1.4178 & 1.4178 & $868.2^{\mathrm{a}}$ & $866.0^{\mathrm{a}}$ & $>99.0$ \\
\hline Ethyl caprate & 1.4252 & 1.4256 & 864.0 & 865.0 & $>99.0$ \\
\hline
\end{tabular}

\footnotetext{
a Measured at $T=291.2 \mathrm{~K}$.
} 


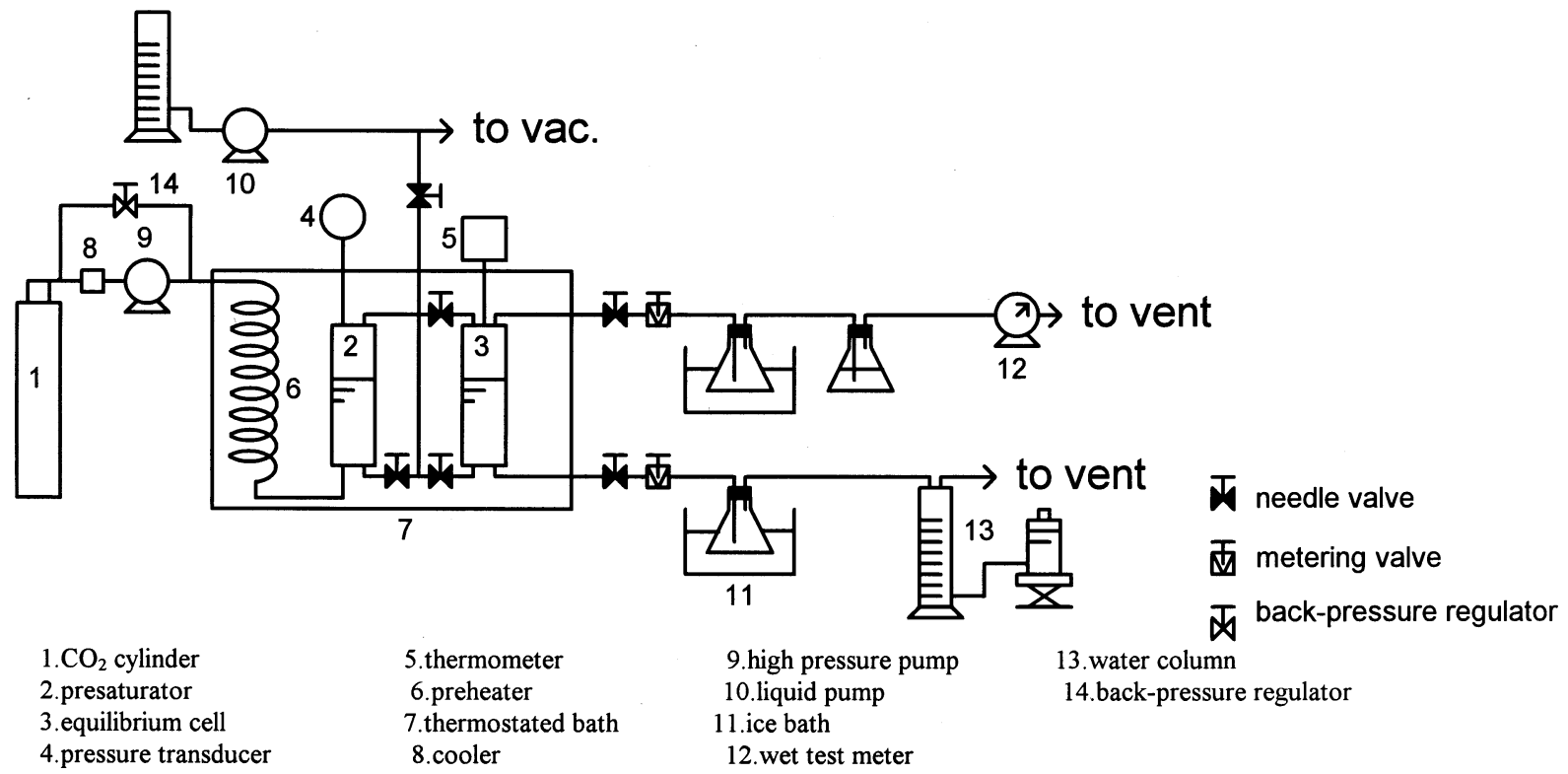

Fig. 1. Schematic diagram of the experimental apparatus.

a constant pressure during the phase equilibrium measurements.

One pre-saturation cell and an equilibrium cell, each with a volume of $300 \mathrm{~cm}^{3}$, were used in this study. The cells (Whitey) were made by stainless steel and were immersed in a water bath at the experimental temperature. The experimental temperature and pressure were measured using a calibrated quartz thermometer (INS), and a calibrated pressure gauge (Heise). The accuracy for temperature and pressure measurements is $\pm 0.1 \mathrm{~K}$ and $\pm 0.02 \mathrm{MPa}$, respectively. The metering valves (Autoclave) and needle valves (Whitey) were also maintained at the experimental temperature to ensure the equilibrium condition.

After the equilibrium cells, pressure was reduced to ambient value and the solvent (ester) component from the liquid or vapor phase sample was collected in a flask and cooled by an ice bath. A wet tester meter (Ritter, TG50) was employed to measure the volume of the solute $\left(\mathrm{CO}_{2}\right)$ in the vapor phase. The volume of the liquid phase was determined by measuring the volume displaced in a column filled with water. The estimated accuracy for these measurements is better than $\pm 0.25 \%$.

\section{Experimental procedures}

Pure liquid solvent of ester compound was firstly fed into the pre-saturation and equilibrium cells using a mini pump. Air in these cells was displaced by the flowing $\mathrm{CO}_{2}$. The pre-equilibrium and equilibrium cells were maintained at a constant temperature in a water bath, and $\mathrm{CO}_{2}$ was charged into the cells under a desired pressure. VLE was usually reached within 2 $\mathrm{h}$, and either the vapor or liquid sample was then expanded to atmospheric pressure through the metering valves. These samples were analyzed using the gravimetric method in this study. The number of moles of the minor ester compound that might vaporize into the gas phase was corrected using the ideal gas equation of state $n=P^{\mathrm{vp}} V / R T$, where, $P^{\mathrm{vp}}$ was the vapor pressure of the ester compound and $V$ was the volume of $\mathrm{CO}_{2}$ measured by the wet tester meter. The reported equilibrium compositions are the average values of at least three repeated measurements. The flow rate of $\mathrm{CO}_{2}$ was maintained about $20 \mathrm{l} \mathrm{h}^{-1}$ during the experiments. It had also been varied from 10 to $40 \mathrm{l} \mathrm{h}^{-1}$, and no change had been observed for the measured compositions. With these procedures, it is ensured that the reported compositions are the equilibrium values. The 
Table 2

Comparison of the VLE measurement results for the binary mixture of $\mathrm{CO}_{2}(1)+1$-octanol (2) at $328.2 \mathrm{~K}$

\begin{tabular}{|c|c|c|c|c|c|}
\hline \multirow[t]{2}{*}{$P(\mathrm{MPa})$} & \multicolumn{2}{|c|}{ Literature data [8] } & \multirow[t]{2}{*}{$P(\mathrm{MPa})$} & \multicolumn{2}{|c|}{ This work } \\
\hline & $x_{1}$ & $y_{1}$ & & $x_{1}$ & $y_{1}$ \\
\hline 4.00 & 0.2406 & 0.9996 & 3.00 & 0.1818 & 0.9996 \\
\hline 6.00 & 0.3533 & 0.9997 & 5.00 & 0.2925 & 0.9997 \\
\hline 8.00 & 0.4785 & 0.9993 & 7.00 & 0.4139 & 0.9995 \\
\hline 10.00 & 0.5856 & 0.9977 & 10.10 & 0.5931 & 0.9979 \\
\hline 12.00 & 0.6674 & 0.9876 & 11.90 & 0.6607 & 0.9909 \\
\hline 15.00 & 0.7772 & 0.9435 & 13.30 & 0.7243 & 0.9755 \\
\hline
\end{tabular}

estimated reproducibility of the measured composition is better than $\pm 2 \%$ for the minor component in the liquid phase, while that for the minor component in the vapor phase is estimated to be $\pm 1.0 \times 10^{-4}$ mole fraction.

\section{Results and discussion}

To ensure the reliability of the experimental data, VLE for carbon dioxide +1 -octanol system was measured at $328.2 \mathrm{~K}$. The experimental results are shown in Table 2, and the graphical presentation is demonstrated in Fig. 2. It is observed that the experimental results using the present apparatus are in satisfactory agreement with those in the previous literature [8]. VLE for three binary mixtures of $\mathrm{CO}_{2}$ with ethyl caproate, ethyl caprylate and ethyl caprate are reported in Tables 3-5, respectively. Graphical presentations of these experimental results are depicted in Figs. 3-5. It is observed that the solubility of carbon dioxide in the liquid phase increases consistently with the decrease of the molecular weight of ester. Carbon dioxide has the largest solubility in ethyl caproate owing to its smallest molecular weight.

In this study, the VLE data were correlated using the equation of state method. The PR equation [5]:

$P=\frac{R T}{v-b}-\frac{a}{v(v+b)+b(v-b)}$

and the SRK [4]:

$P=\frac{R T}{v-b}-\frac{a}{v(v+b)}$

were employed to correlate the experimental results. Critical properties and acentric factor employed are listed in Table 6.
Table 3

Experimental VLE results for the binary mixture of $\mathrm{CO}_{2}(1)+$ ethyl caproate (2)

\begin{tabular}{|c|c|c|c|}
\hline \multirow[t]{2}{*}{ Pressure (MPa) } & \multicolumn{2}{|c|}{ Composition } & \multirow{2}{*}{$\begin{array}{l}\text { Equilibrium } \\
\text { ratio } K_{1}\end{array}$} \\
\hline & $x_{1}$ & $y_{1}$ & \\
\hline \multicolumn{4}{|l|}{$T=308.2 \mathrm{~K}$} \\
\hline 1.699 & 0.2823 & 0.9994 & 3.540 \\
\hline 2.414 & 0.3834 & 0.9994 & 2.607 \\
\hline 3.060 & 0.4750 & 0.9994 & 2.104 \\
\hline 3.706 & 0.5558 & 0.9994 & 1.798 \\
\hline 4.404 & 0.6282 & 0.9994 & 1.591 \\
\hline 5.117 & 0.7050 & 0.9994 & 1.418 \\
\hline 5.748 & 0.7832 & 0.9991 & 1.276 \\
\hline 6.462 & 0.8480 & 0.9990 & 1.178 \\
\hline \multicolumn{4}{|l|}{$T=318.2 \mathrm{~K}$} \\
\hline 1.699 & 0.2301 & 0.9992 & 4.342 \\
\hline 2.380 & 0.3163 & 0.9992 & 3.159 \\
\hline 3.026 & 0.4023 & 0.9992 & 2.484 \\
\hline 3.740 & 0.4719 & 0.9992 & 2.117 \\
\hline 4.387 & 0.5341 & 0.9991 & 1.871 \\
\hline 5.101 & 0.6036 & 0.9991 & 1.655 \\
\hline 5.816 & 0.6671 & 0.9987 & 1.497 \\
\hline 6.462 & 0.7346 & 0.9985 & 1.359 \\
\hline 7.177 & 0.7965 & 0.9984 & 1.253 \\
\hline 7.823 & 0.8541 & 0.9976 & 1.168 \\
\hline \multicolumn{4}{|l|}{$T=328.2 \mathrm{~K}$} \\
\hline 1.733 & 0.2090 & 0.9987 & 4.778 \\
\hline 2.414 & 0.2920 & 0.9987 & 3.420 \\
\hline 3.094 & 0.3635 & 0.9986 & 2.747 \\
\hline 3.758 & 0.4318 & 0.9986 & 2.313 \\
\hline 4.438 & 0.4882 & 0.9986 & 2.045 \\
\hline 5.135 & 0.5504 & 0.9985 & 1.814 \\
\hline 5.799 & 0.6054 & 0.9982 & 1.649 \\
\hline 6.496 & 0.6540 & 0.9982 & 1.526 \\
\hline 7.177 & 0.7039 & 0.9982 & 1.418 \\
\hline 7.823 & 0.7571 & 0.9981 & 1.318 \\
\hline 8.538 & 0.8093 & 0.9964 & 1.231 \\
\hline 9.218 & 0.8463 & 0.9963 & 1.177 \\
\hline
\end{tabular}




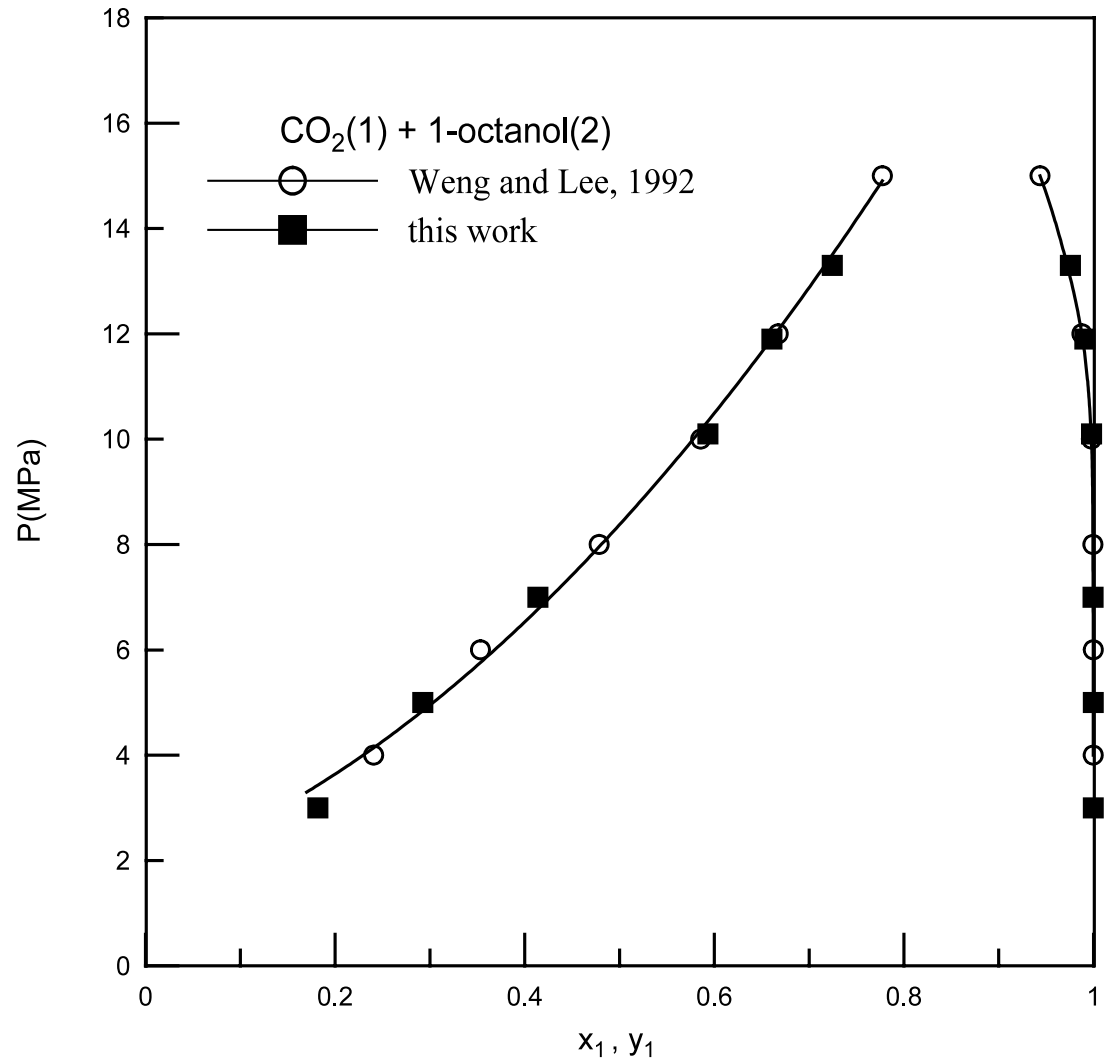

Fig. 2. Comparison of the Pxy data for the binary mixture of carbon dioxide (1) +1-octanol (2) at $328.2 \mathrm{~K}$.

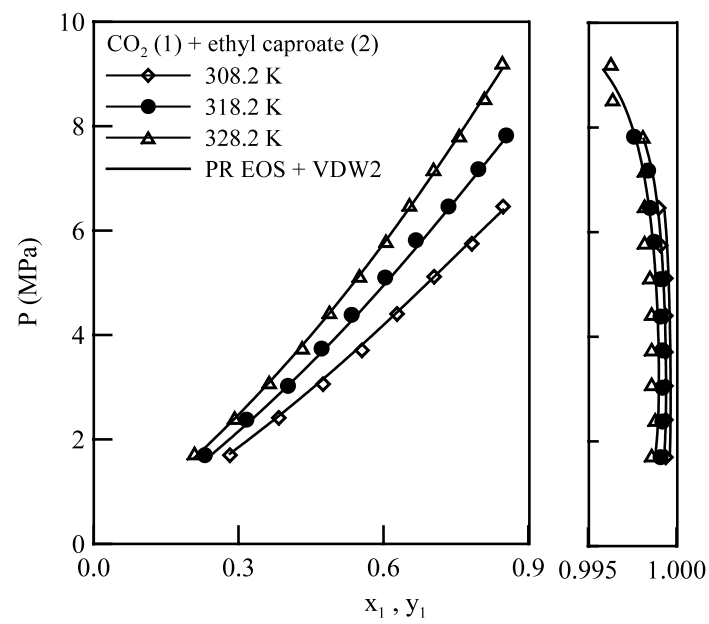

Fig. 3. VLE results of the binary mixture of $\mathrm{CO}_{2}(1)+$ ethyl caproate (2).

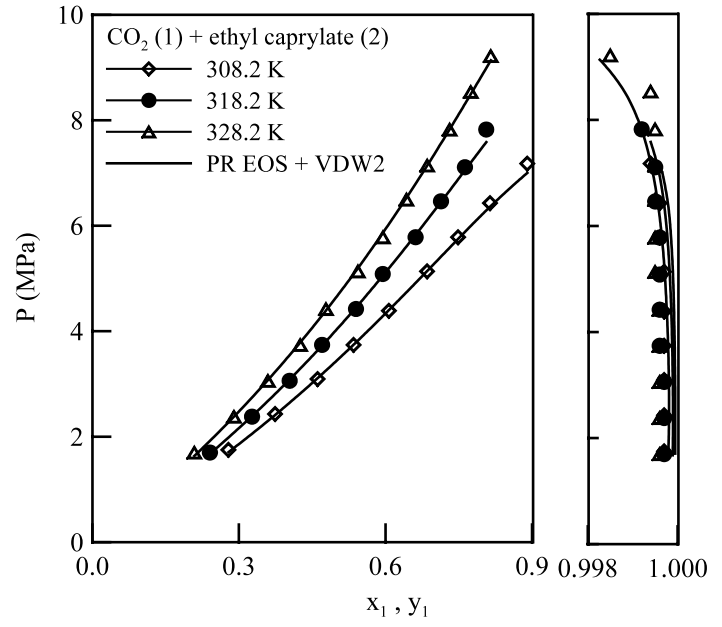

Fig. 4. VLE results of the binary mixture of $\mathrm{CO}_{2}(1)+$ ethyl caprylate (2). 
Table 4

Experimental VLE results for the binary mixture of $\mathrm{CO}_{2}(1)+$ ethyl caprylate (2)

\begin{tabular}{|c|c|c|c|}
\hline \multirow[t]{2}{*}{ Pressure (MPa) } & \multicolumn{2}{|c|}{ Composition } & \multirow{2}{*}{$\begin{array}{l}\text { Equilibrium } \\
\text { ratio } K_{1}\end{array}$} \\
\hline & $x_{1}$ & $y_{1}$ & \\
\hline \multicolumn{4}{|l|}{$T=308.2 \mathrm{~K}$} \\
\hline 1.750 & 0.2786 & 0.9997 & 3.588 \\
\hline 2.431 & 0.3740 & 0.9997 & 2.673 \\
\hline 3.094 & 0.4612 & 0.9997 & 2.168 \\
\hline 3.740 & 0.5348 & 0.9997 & 1.869 \\
\hline 4.387 & 0.6072 & 0.9997 & 1.646 \\
\hline 5.135 & 0.6853 & 0.9997 & 1.459 \\
\hline 5.782 & 0.7488 & 0.9996 & 1.335 \\
\hline 6.428 & 0.8140 & 0.9996 & 1.228 \\
\hline 7.177 & 0.8904 & 0.9994 & 1.122 \\
\hline \multicolumn{4}{|l|}{$T=318.2 \mathrm{~K}$} \\
\hline 1.699 & 0.2407 & 0.9997 & 4.153 \\
\hline 2.380 & 0.3269 & 0.9997 & 3.058 \\
\hline 3.060 & 0.4039 & 0.9997 & 2.475 \\
\hline 3.740 & 0.4703 & 0.9996 & 2.125 \\
\hline 4.421 & 0.5397 & 0.9996 & 1.852 \\
\hline 5.084 & 0.5945 & 0.9996 & 1.681 \\
\hline 5.782 & 0.6617 & 0.9996 & 1.511 \\
\hline 6.462 & 0.7137 & 0.9995 & 1.400 \\
\hline 7.109 & 0.7627 & 0.9995 & 1.310 \\
\hline 7.823 & 0.8063 & 0.9992 & 1.239 \\
\hline \multicolumn{4}{|l|}{$T=328.2 \mathrm{~K}$} \\
\hline 1.699 & 0.2088 & 0.9996 & 4.787 \\
\hline 2.380 & 0.2898 & 0.9996 & 3.449 \\
\hline 3.060 & 0.3595 & 0.9996 & 2.781 \\
\hline 3.740 & 0.4254 & 0.9996 & 2.350 \\
\hline 4.421 & 0.4783 & 0.9996 & 2.090 \\
\hline 5.135 & 0.5437 & 0.9995 & 1.838 \\
\hline 5.782 & 0.5949 & 0.9995 & 1.680 \\
\hline 6.496 & 0.6430 & 0.9995 & 1.554 \\
\hline 7.143 & 0.6855 & 0.9995 & 1.458 \\
\hline 7.823 & 0.7314 & 0.9995 & 1.367 \\
\hline 8.538 & 0.7748 & 0.9994 & 1.290 \\
\hline 9.218 & 0.8156 & 0.9985 & 1.224 \\
\hline
\end{tabular}

Various mixing rules were applied in this study to evaluate the equation of state parameters for mixtures. The van der Waals one-fluid (VDW1) mixing rules with one binary parameter $k_{i j}$ are given by:

$$
\begin{aligned}
& a_{\mathrm{m}}=\sum \sum x_{i} x_{j}\left(a_{i} a_{j}\right)^{0.5}\left(1-k_{i j}\right) \\
& b_{\mathrm{m}}=\sum x_{i} b_{i}
\end{aligned}
$$

The volume parameter of a mixture can also be evaluated using an additional binary parameter $m_{i j}$ (VDW2 mixing rule):
Table 5

Experimental VLE results for the binary mixture of $\mathrm{CO}_{2}(1)+$ ethyl

\begin{tabular}{|c|c|c|c|}
\hline \multirow[t]{2}{*}{ Pressure (MPa) } & \multicolumn{2}{|c|}{ Composition } & \multirow{2}{*}{$\begin{array}{l}\text { Equilibrium } \\
\text { ratio } K_{1}\end{array}$} \\
\hline & $x_{1}$ & $y_{1}$ & \\
\hline \multicolumn{4}{|l|}{$T=308.2 \mathrm{~K}$} \\
\hline 1.665 & 0.2580 & 0.9998 & 3.875 \\
\hline 2.346 & 0.3452 & 0.9998 & 2.896 \\
\hline 3.026 & 0.4236 & 0.9998 & 2.360 \\
\hline 3.723 & 0.5017 & 0.9998 & 1.993 \\
\hline 4.387 & 0.5797 & 0.9998 & 1.725 \\
\hline 5.067 & 0.6543 & 0.9998 & 1.528 \\
\hline 5.748 & 0.7202 & 0.9998 & 1.388 \\
\hline 6.428 & 0.7865 & 0.9998 & 1.271 \\
\hline 7.109 & 0.8454 & 0.9998 & 1.183 \\
\hline \multicolumn{4}{|l|}{$T=318.2 \mathrm{~K}$} \\
\hline 1.699 & 0.2297 & 0.9998 & 4.353 \\
\hline 2.380 & 0.3116 & 0.9998 & 3.209 \\
\hline 3.060 & 0.3831 & 0.9998 & 2.610 \\
\hline 3.757 & 0.4537 & 0.9998 & 2.204 \\
\hline 4.421 & 0.5182 & 0.9998 & 1.929 \\
\hline 5.084 & 0.5746 & 0.9998 & 1.740 \\
\hline 5.782 & 0.6304 & 0.9998 & 1.586 \\
\hline 6.462 & 0.6852 & 0.9998 & 1.459 \\
\hline 7.143 & 0.7302 & 0.9997 & 1.369 \\
\hline 7.891 & 0.7775 & 0.9996 & 1.286 \\
\hline \multicolumn{4}{|l|}{$T=328.2 \mathrm{~K}$} \\
\hline 1.699 & 0.2068 & 0.9998 & 4.835 \\
\hline 2.380 & 0.2819 & 0.9998 & 3.547 \\
\hline 3.060 & 0.3482 & 0.9998 & 2.871 \\
\hline 3.740 & 0.4096 & 0.9998 & 2.441 \\
\hline 4.421 & 0.4622 & 0.9998 & 2.163 \\
\hline 5.101 & 0.5176 & 0.9998 & 1.932 \\
\hline 5.782 & 0.5705 & 0.9997 & 1.752 \\
\hline 6.462 & 0.6150 & 0.9997 & 1.626 \\
\hline 7.177 & 0.6620 & 0.9997 & 1.510 \\
\hline 8.538 & 0.7460 & 0.9995 & 1.340 \\
\hline 9.218 & 0.7780 & 0.9992 & 1.284 \\
\hline
\end{tabular}
caprate (2)

$b_{\mathrm{m}}=\sum \sum x_{i} x_{j} \frac{\left(b_{i}+b_{j}\right)}{2}\left(1-m_{i j}\right)$

Panagiotopoulos and Reid [9] assumed that the binary parameters are composition-dependent (Panagiotopoulos-Reid mixing rule), the mixture volume parameter for an equation of state was determined by Eq. (4), and the mixture energy parameter was written as:

$$
a_{\mathrm{m}}=\sum \sum x_{i} x_{j}\left(a_{i} a_{j}\right)^{0.5}\left[1-k_{i j}+\left(k_{i j}-k_{j i}\right) x_{i}\right]
$$




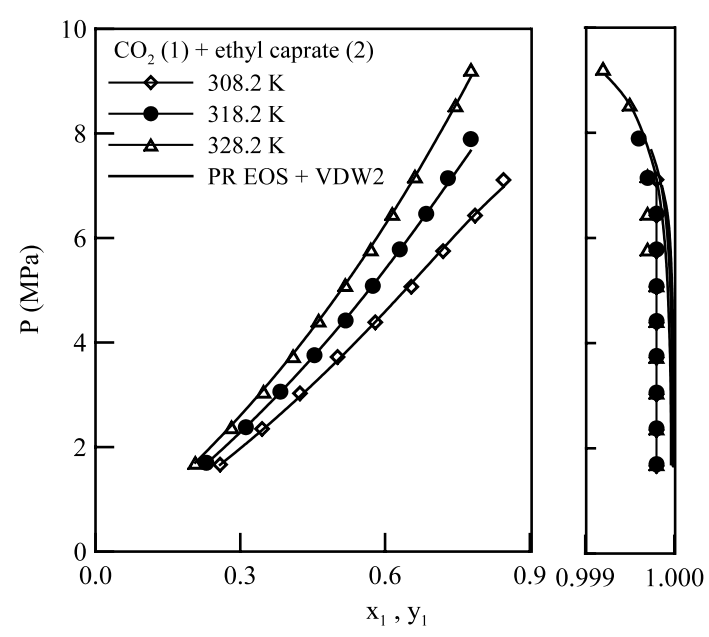

Fig. 5. VLE results of the binary mixture of $\mathrm{CO}_{2}(1)+$ ethyl caprate (2).

Although this mixing rule has limit in extension to multi-component systems, it is applicable in correlating binary phase equilibrium data.

In addition to the traditional van der Waals type mixing rules, a group contribution mixing model proposed by Huron and Vidal [10] is also widely employed. In this mixing model, the excess free energy calculated from an equation of state at an infinite pressure reference state was set equal to that from an activity coeffi-
Table 6

Pure component properties used in this work

\begin{tabular}{llll}
\hline Component & $T_{\mathrm{c}}(\mathrm{K})$ & $P_{\mathrm{c}}(\mathrm{MPa})$ & $\omega$ \\
\hline Carbon dioxide & $304.19[14]$ & $7.382[14]$ & $0.228[14]$ \\
Ethyl caproate & $611.62[15]$ & $2.548[15]$ & $0.555[16]$ \\
Ethyl caprylate & $648.64[15]$ & $2.118[15]$ & $0.653[16]$ \\
Ethyl caprate & $680.82[15]$ & $1.788[15]$ & $0.742[16]$ \\
\hline
\end{tabular}

cient model. The NRTL [11] and UNIQUAC [12] activity coefficient models were employed in this study with the PR and SRK cubic equations of state. The optimal binary parameters in the NRTL and the UNIQUAC models were regressed from the experimental VLE data. The following objective function was used in the data regression:

obj $=\sum\left|\frac{P^{\exp }-P^{\text {cal }}}{P^{\exp }}\right|_{i}+\sum\left|y_{2}^{\exp }-y_{2}^{\text {cal }}\right|_{i}$

The binary parameters of EOS in this study were taken as temperature-independent, and their optimal values were evaluated from data regression. The binary parameters of the van der Waals type mixing rules are presented in Table 7. It is observed that either the PR or SRK equation with van der Waals mixing rules and two binary parameters yields satisfactory results. The optimal NRTL and UNIQUAC parameters regressed from the Huron-Vidal method are shown in

Table 7

Correlated results of experimental VLE data of three binary mixtures using various EOS and mixing rules

\begin{tabular}{|c|c|c|c|c|c|c|c|c|c|c|}
\hline \multirow[t]{2}{*}{ Mixing rules } & \multicolumn{5}{|c|}{ Peng-Robinson EOS } & \multicolumn{5}{|c|}{ Soave-Redlich-Kwong EOS } \\
\hline & $k_{12}$ & $k_{21}$ & $m_{12}$ & $\operatorname{AADP}(\%)$ & $\mathrm{AAD} y_{1}(\%)$ & $k_{12}$ & $k_{21}$ & $m_{12}$ & $\operatorname{AADP}(\%)$ & $\mathrm{AAD}_{1}(\%)$ \\
\hline \multicolumn{11}{|c|}{$\mathrm{CO}_{2}(1)+$ ethyl caproate $(2)$} \\
\hline VDW1 & 0.025 & & \multirow{3}{*}{0.007} & 1.79 & 0.03 & 0.028 & & \multirow{3}{*}{0.006} & 1.77 & 0.04 \\
\hline VDW2 & 0.030 & & & 1.51 & 0.03 & 0.032 & & & 1.53 & 0.04 \\
\hline Panagiotopoulos-Reid & 0.013 & 0.027 & & 1.53 & 0.03 & 0.016 & 0.029 & & 1.55 & 0.04 \\
\hline \multicolumn{11}{|c|}{$\mathrm{CO}_{2}(1)+$ ethyl caprylate $(2)$} \\
\hline VDW1 & 0.030 & & \multirow{3}{*}{0.010} & 1.99 & 0.02 & 0.034 & & \multirow{3}{*}{0.010} & 1.93 & 0.02 \\
\hline VDW2 & 0.040 & & & 0.91 & 0.02 & 0.044 & & & 0.84 & 0.02 \\
\hline Panagiotopoulos-Reid & 0.010 & 0.035 & & 0.93 & 0.02 & 0.013 & 0.040 & & 0.87 & 0.02 \\
\hline \multicolumn{11}{|c|}{$\mathrm{CO}_{2}(1)+$ ethyl caprate $(2)$} \\
\hline VDW1 & 0.044 & & \multirow{3}{*}{0.007} & 1.85 & 0.02 & 0.050 & & \multirow{3}{*}{0.007} & 1.82 & 0.02 \\
\hline VDW2 & 0.050 & & & 0.80 & 0.02 & 0.057 & & & 0.77 & 0.02 \\
\hline Panagiotopoulos-Reid & 0.027 & 0.048 & & 0.80 & 0.02 & 0.032 & 0.055 & & 0.78 & 0.02 \\
\hline
\end{tabular}


Table 8

Correlated results of the experimental VLE data of three binary mixtures by the Huron-Vidal mixing rules with the NRTL and the UNIQUAC activity coefficient models

\begin{tabular}{|c|c|c|c|c|c|}
\hline EOS & $A_{12}\left(\mathrm{~J} \mathrm{~mol}^{-1}\right)$ & $A_{21}\left(\mathrm{~J} \mathrm{~mol}^{-1}\right)$ & $\alpha$ & AADP $(\%)$ & $\mathrm{AAD}_{y_{1}}(\%)$ \\
\hline \multicolumn{6}{|c|}{ NRTL model } \\
\hline \multicolumn{6}{|c|}{$\mathrm{CO}_{2}(1)+$ ethyl caproate $(2)$} \\
\hline PR & 7819.25 & -3024.83 & 0.3 & 2.23 & 0.03 \\
\hline SRK & 7358.27 & -3053.93 & 0.3 & 2.08 & 0.04 \\
\hline \multicolumn{6}{|c|}{$\mathrm{CO}_{2}(1)+$ ethyl caprylate $(2)$} \\
\hline PR & 10342.78 & -3158.44 & 0.3 & 3.56 & 0.02 \\
\hline SRK & 9227.62 & -3140.30 & 0.3 & 2.97 & 0.02 \\
\hline \multicolumn{6}{|c|}{$\mathrm{CO}_{2}(1)+$ ethyl caprate $(2)$} \\
\hline PR & 10469.41 & -2476.58 & 0.3 & 4.50 & 0.02 \\
\hline SRK & 10586.58 & -2678.63 & 0.3 & 3.92 & 0.02 \\
\hline \multicolumn{6}{|c|}{ UNIQUAC model } \\
\hline \multicolumn{6}{|c|}{$\mathrm{CO}_{2}(1)+$ ethyl caproate $(2)$} \\
\hline PR & 895.55 & 1104.45 & & 1.75 & 0.03 \\
\hline SRK & 719.28 & 1197.66 & & 1.76 & 0.04 \\
\hline \multicolumn{6}{|c|}{$\mathrm{CO}_{2}(1)+$ ethyl caprylate $(2)$} \\
\hline PR & 1150.17 & 1365.97 & & 1.17 & 0.02 \\
\hline SRK & 1006.54 & 1381.18 & & 1.10 & 0.02 \\
\hline \multicolumn{6}{|c|}{$\mathrm{CO}_{2}(1)+$ ethyl caprate $(2)$} \\
\hline PR & 1365.32 & 1775.22 & & 1.05 & 0.02 \\
\hline SRK & 1223.16 & 1757.02 & & 0.98 & 0.02 \\
\hline
\end{tabular}

$\operatorname{AADP}(\%)=\frac{100}{n} \sum_{i=1}^{n} \frac{\left|P^{\exp }-P^{c a l}\right|_{i}}{P_{i}^{\exp }}, \operatorname{AAD}_{1}(\%)=\frac{100}{n} \sum_{i-1}^{n} \frac{\left|y_{1}^{\exp }-y_{1}^{c a l}\right|_{i}}{y_{1, i}^{\exp }}$

Table 8. It is shown that the results with the NRTL model show a relatively larger deviation than those from the van der Waals mixing rules. The Huron-Vidal type mixing rule with the UNIQUAC model shows comparably good results with the conventional van der Waals mixing rules. Graphical presentations of the calculated results from the PR equation of state with dual interaction parameters are also shown in Figs. 3-5. It is demonstrated that the experimental gas solubility data are well correlated using cubic equation of state model.

\section{Conclusion}

Experimental VLE data for three binary systems of carbon dioxide with ethyl caproate, ethyl caprylate, and ethyl caprate are reported at 308.2, 318.2, and $328.2 \mathrm{~K}$ and pressures up to 9.2 MPa. The PR and SRK equations of state with various mixing models were used to correlate the experimental data. Both equations of state with the van der Waals mixing rules and two optimally fitted parameters, or the Huron-Vidal type mixing rules with the UNIQUAC model yield satisfactory regression results.

\section{Acknowledgements}

The authors are grateful to the National Science Council, ROC for supporting this research.

\section{References}

[1] Z. Wagner, Vapour-liquid equilibrium at high pressure in the system containing carbon dioxide and propyl acetate, Fluid Phase Equilib. 110 (1995) 175-182. 
[2] V. Riha, G. Brunner, Phase equilibrium of fish oil ethyl esters with supercritical carbon dioxide, J. Supercrit. Fluids 15 (1999) 33-50.

[3] R.M.M. Stevens, X.M. Shen, T.W. de Loos, J. de Swaan Arons, A new apparatus to measure the vapor-liquid equilibria of low volatility compounds with near critical carbon dioxide, experimental and modeling results for carbon dioxide $+n$ butanol, +2-butanol, +2-butyl acetate and +vinyl acetate systems, J. Supercrit. Fluids 11 (1997) 1-14.

[4] G. Soave, Equilibrium constants from a modified RedlichKwong equation of state, Chem. Eng. Sci. 27 (1972) 11971203.

[5] D.Y. Peng, D.B. Robinson, A new two constant equation of state, Ind. Eng. Chem. Fundam. 15 (1976) 59-64.

[6] K.W. Cheng, S.J. Kuo, M. Tang, Y.P. Chen, Vapor-liquid equilibria at elevated pressure of binary mixture of carbon dioxide with methyl salicylate, eugenol, and diethyl phthalate, J. Supercrit. Fluids 18 (2000) 87-99.

[7] K.W. Cheng, M. Tang, Y.P. Chen, Vapor-liquid equilibria of carbon dioxide with diethyl oxalate, ethyl laurate, and dibutyl phthalate binary mixtures at elevated pressures, Fluid Phase Equilib. 181 (2001) 1-16.

[8] W.L. Weng, M.J. Lee, Phase equilibrium measurement for the binary mixtures of 1-octanol plus $\mathrm{CO}_{2}, \mathrm{C}_{2} \mathrm{H}_{6}$ and $\mathrm{C}_{2} \mathrm{H}_{4}$, Fluid Phase Equilib. 73 (1992) 117-125.
[9] A.Z. Panagiotopoulos, R.C. Reid, New mixing rule for cubic equation of state for highly polar asymmetric systems, ACS Symp. Ser. 300 (1986) 571-582.

[10] M.J. Huron, J. Vidal, New mixing rules in simple equation of state for representing vapor-liquid equilibria of strongly non-ideal mixtures, Fluid Phase Equilib. 3 (1979) 255271.

[11] H. Renon, J.M. Prausnitz, Local compositions in thermodynamic excess functions for liquid mixture, Am. Inst. Chem. Eng. J. 14 (1968) 135-144.

[12] D.S. Abrams, J.M. Prausnitz, Statistical thermodynamic of liquid mixture: a new expression for the excess Gibbs energy of partly or completely miscible system, Am. Inst. Chem. Eng. J. 21 (1975) 116-128.

[13] D.R. Lide, H.P.R. Frederikse, CRC Handbook of Chemistry and Physics, 80th ed, CRC Press, Boca Raton, FL, 1999.

[14] T.E. Daubert, R.P. Danner, Physical and Thermodynamic Properties of Pure Chemicals: Data Compilation, Hemisphere, New York, 1989.

[15] R.C. Reid, J.M. Prasunitz, B.E. Poling, The Properties of Gases and Liquids, fourth ed, McGraw-Hill, New York, 1987.

[16] B.I. Lee, M.G. Kesler, A generalized thermodynamic correlation based on three-parameter corresponding states, Am. Inst. Chem. Eng. J. 21 (1975) 510-527. 